\title{
Research on the relationship between precipitation and landslide
}

\author{
Yubin Zhang ${ }^{1 *}$ \\ ${ }^{1}$ National Earthquake Response Support Service, Beijing 100049, P. R. China
}

\begin{abstract}
This paper introduces the inducing factors of landslide disaster and the terrain characteristics of landslide. The characteristics of landslides in southern and Western China are mainly introduced. The influence of vegetation covered slope soil on rainwater infiltration was studied. By analyzing the relationship between soil porosity and soil permeability, it can be used as a basis for assessing landslide risk. At the same time, the concept of soil and water cycle was introduced in combination with induced factors. These studies are of great significance for improving the accuracy of landslide warning in the future.
\end{abstract}

\section{Landslide disaster}

\subsection{Landslide}

Landslide refers to the phenomenon that the soil or rock mass on the slope slides downward along a certain weak surface (sliding surface) under the action of gravity. Most landslides occur between $10^{\circ}$ and $45^{\circ}$ slope [1]. Slope soil is eroded by surface water and groundwater for a long time, and landslides occur when induced conditions occur. The inducing factors include strong precipitation, accumulated precipitation, earthquake, human engineering and other disturbance factors. The landslide site structure is composed of landslide back wall, material source area, landslides side wall, sliding surface, landslide mass, flow area and accumulation area [2]. As shown in Figure 1.

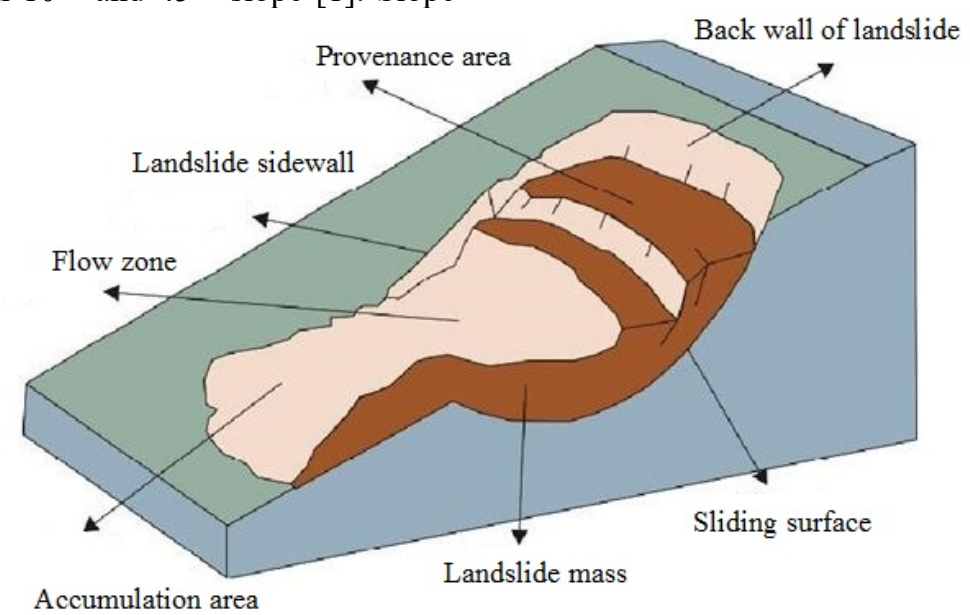

Figure 1. Landslide site structure

\subsection{Disaster characteristics of landslides}

The main characteristics of landslide disaster include three aspects: difficult to predict, instantaneous sudden and difficult to rescue. From these characteristics, we can easily find that landslide disaster is cruel. Landslide disaster is a kind of cumulative and sudden disaster, which occurs immediately after reaching the critical point. Because there are many kinds of terrain and vast mountainous area in China, the frequency of landslide disaster is high. In recent ten years, the number of landslides in China has gradually decreased. Because of the great harm of landslide, we still need to pay attention to it. There are many factors that lead to landslide, so it is of great significance to analyze the basic factors causing landslide.

\subsection{Influencing factors of landslide}

The occurrence of disasters is generally caused by both natural and human factors. Human factors are mainly caused by the large number of side slope cutting houses in the mountain area and some unreasonable engineering 
design had caused environmental damage. Natural factors include geological environment and climate. The geological environment mainly refers to slope, aspect, elevation, catchment area, gully morphology, etc. Geological environment restricts the formation and movement of landslides, so that each landslide has its own characteristics. Climate conditions mainly refer to the water source conditions under the natural environment. The main sources of water are meteoric water, including rainwater, groundwater and snow melt water. The effect of water source condition on the development of landslide is reflected in reducing the shear strength of sliding surface and increasing the weight of sliding mass. Supersaturated water in slope soil is the main cause of landslide. Compared with the geological environment, the atmospheric precipitation is changeable and predictable [3]. Therefore, it is of great significance to study the relationship between precipitation and landslides for the early warning of landslide disasters.

\subsubsection{Earthquake is one of the causes of landslides.} China is located in the active region of the earth plate movement, and earthquakes often occur. The earthquake leads to the development of rock and soil cracks and gravel stacking, which provides material conditions for the occurrence of landslide. Landslides occur frequently in Western and southern China. On the one hand, the rugged terrain, high mountains and deep valleys, large slope, provide the terrain conditions for the occurrence of landslide. On the other hand, sufficient precipitation provides dynamic conditions for the occurrence of landslide.

1.3.2. Human engineering. The human causes of landslide mainly include unreasonable land development and mountain highway construction. The stability of the geological structure is affected by the engineering activities such as random excavation of slope toe and random stacking of waste soil. The influence of geological structure on landslide disaster is mainly indirect. When the folds and faults in the existing geological structure are destroyed, the rock around the slope will not belong to stable structure. In this case, if there is precipitation or earthquake, landslide will be induced.

\section{Relationship between soil permeability and landslides}

\subsection{Soil porosity and water permeability}

The movement of liquid water in soil generally occurs between soil particles and in structural pores. Assuming that there are no macropore in the soil, the movement of liquid water in soil pores is approximately consistent with Darcy-Weisbach formula.

The storage and movement of liquid water in soil is determined by the pore size between particles. It is assumed that there are macropore in the soil. Water flow does not interact with water in the surrounding soil matrix. The water in macropores in soil can produce macropore flow in a short time and move down to deeper soil.

In the process of precipitation infiltration, the movement of soil water is mainly determined by the properties of macropores and other fissures.

It is particularly important to note that when the moisture content in the soil tends to be saturated, the flow velocity and water flow in the soil macropores are much larger than that in the soil matrix. The existence of macropore flow promotes the response speed of groundwater level to precipitation.

\subsection{Precipitation and water permeability}

Although porosity accounts for a small proportion of soil volume, it has great influence on the movement of water in soil. Scholar Luxmoore pointed out that although the ratio of pore water flow greater than $1 \mathrm{~mm}$ to total pore flow is smaller, it has an important effect on water infiltration and migration [4]. The existence of macropore channels in the slope soil with vegetation development enables water to move to a depth of 5 meters below the surface in a short time. The groundwater circulation system in forest area has the characteristics of rapid infiltration.

The existence of macropores accelerates the downward penetration of water. When the precipitation is less than the permeability of soil, the depth and flow of water in macropores depend on precipitation. The pore water flow increases with the increase of precipitation, and the seepage depth increases accordingly. The process of precipitation infiltration will form underground runoff in soil. Underground runoff is easy to cause soil erosion or landslide and other geological disasters. There is non-equilibrium water transport in soil. The rapid accumulation of water in a certain soil layer leads to significant changes in groundwater level in the slope. This water level fluctuation will reduce the stability of soil. The existence of macropores in soil directly affects the stability of surface water and groundwater runoff, and is the internal dynamic factor causing geological disasters such as landslides.

\subsection{Plant cover and slope stability}

Plants play an important role in stabilizing the slope structure. Under the condition of precipitation, plants have strong water storage function. The defoliation and decay of plants have a profound impact on the infiltration process of precipitation in soil [5]. Plants can effectively change the physical and chemical properties of soil. The root distribution of plants is the basis of water cycle and the core of stabilizing soil structure. The existence of plants greatly increased the porosity of the soil, thus enhancing the permeability of the soil and improving the storage capacity of the slope.

Scholar Zhitao Liu pointed out that the regulation function of forest to flood is related to rainstorm and soil moisture content in the early stage of the basin [6]. If the 
soil moisture content is low, the soil water storage capacity is strong, and the soil can play a role in weakening the surface runoff. On the contrary, if the soil moisture content is saturated before precipitation, the water storage function of the forest is very little.

\section{Influence principle of precipitation on landslide}

China has a large land area and belongs to monsoon climate. The spatial and temporal distribution of water resources is uneven, and the natural environment between the north and the south is quite different. There are many kinds of index parameters to show the precipitation grade, such as precipitation, precipitation intensity and temporal and spatial distribution of precipitation. In the risk study of landslide disaster, the average precipitation and precipitation intensity are generally used to show the precipitation characteristics of relevant areas. The south of China has abundant rainfall and the mountainous area is widely distributed, which is prone to landslide. As shown in Figure 2.

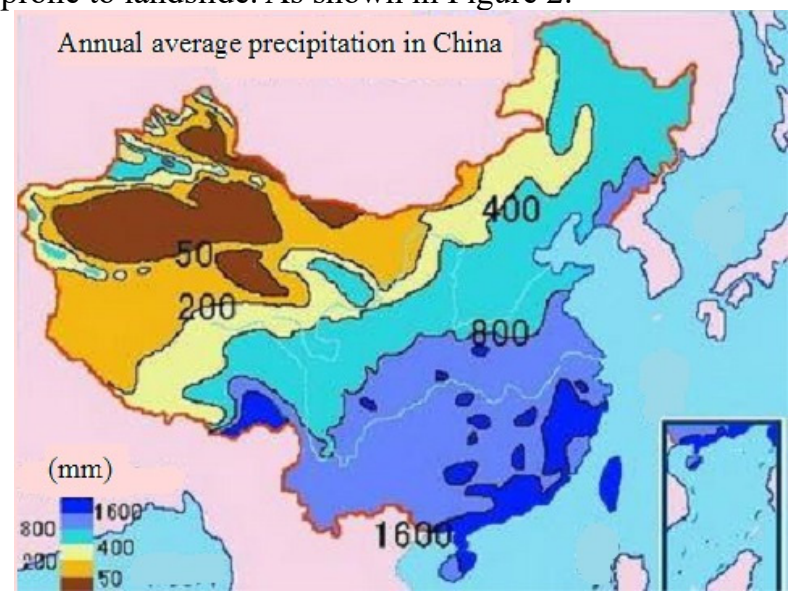

Figure 2. Annual average precipitation in china

On the other hand, the Himalayas and Altay Mountains are located in the western part of China, with large ice and snow coverage. In spring and summer, a large amount of glacial melt water will be produced, which promotes the displacement of slope surface and breeds the occurrence of landslide.

\subsection{Precipitation and geological disasters}

Precipitation is one of the main inducing factors of geological disasters. There is a linear relationship between the scale of geological disasters and rainfall intensity. Rainfall infiltration will reduce the shear strength of soil and the friction resistance between soil and bedrock, and increase the gravity of soil, which will induce geological disasters [7].

Hydrological conditions are the catalyst for the formation of geological disasters. The impact on the formation of geological disasters is mainly manifested in the erosion degree of surface water activities on bedrock and slope [8]. Because of the greenhouse gas effect, the temperature is increasing year by year, and the glacier ablation has also promoted the occurrence of landslide disasters. According to the statistics of the last 20 years, the occurrence of landslides in China is negatively correlated with the distance from the river. The farther the slope is from the river, the lower the possibility of disaster.

\subsection{Precipitation and landslide}

A large amount of surface water generated by precipitation will infiltrate the rock and soil mass on the slope and increase the weight of the slope. Precipitation will cause the softening of rock and soil, reduce the mechanical strength of rock and soil mass, and the slope will become unstable and eventually form landslide disaster.

3.2.1. Precipitation. Precipitation intensity refers to the precipitation per unit time. The greater the rainfall intensity, the greater the disaster risk. The higher precipitation intensity will accelerate the formation of surface runoff and accelerate the supersaturation of aquifer. In coastal areas, it is easy to be affected by tropical cyclones, and heavy rainfall occurs in a short period of time. As a result of the above reasons, urban waterlogging and rural landslides occurred.

3.2.2. Glacier melting. Western China belongs to the plateau region, and the Himalayas produce a lot of glacier melt water every year. In the high temperature season, on the one hand, floods will occur and erode the geological structure along the river. On the other hand, the repeated change of air temperature will cause the rock and soil to expand and contract by heat. With the infiltration of glacier melt water, the weathering of rock will be accelerated, and a large number of gravel blocks will be formed. Combined with the above two reasons, the risk of landslides in mountainous areas and rivers in Western China is very high.

3.2.3. At present, the important means of landslide early warning is to analyze the landslide risk by observing the precipitation state. In the risk area, risk assessment is carried out by analyzing the numerical relationship between precipitation intensity and precipitation in time and space.

The academia has been committed to the study of the critical value of precipitation for landslide warning. In order to determine the critical precipitation threshold value of landslide, the mathematical model is generally used for simulation calculation. At present, landslip warning is mainly based on the threshold value model of daily precipitation, pre precipitation threshold model and main body moisture content model. Although there are many early warning analysis models, the accuracy of early warning is not high. The reason for the inaccuracy is that the constructed critical precipitation, precipitation intensity threshold and precipitation duration do not come from the target area. The superposition effect of 
precipitation in time and space is not considered. Therefore, it is still difficult to calculate landslide risk by precipitation. At present, the dangerous area can only be determined by risk calculation, but the landslide point and occurrence time can not be determined. The accuracy of real-time information directly affects the final calculation results. Real time information includes climate information, disaster information and even public opinion information in disaster area. If this kind of real-time information is not accurate, it is a risk [9]. At present, it is the basis of improving landslide early warning to arrange more precipitation observation equipment in risk areas and residential areas.

\section{Conclusion}

This paper first introduces the characteristics of landslide disasters and disaster causing factors. The permeability of pore water in soil is analyzed. At the same time, the concept of soil and water cycle is introduced in combination with disaster causing factors. Landslide risk analysis based on the data of precipitation intensity and precipitation quantity is the main technology of landslide early warning. Through the comprehensive analysis of soil permeability and geological structure, it is of great significance to improve the accuracy of early warning. In the future, more data acquisition equipment will be deployed to expand the collection range of precipitation data in dangerous areas and improve the accuracy of prediction model calculation results.

\section{References}

1. Zhang, Y. (2016) Exploration and treatment design of a geological hazard in the north of Henan Province, Thesis of Zhengzhou University, Zhengzhou.

2. Guo, C.B., Du, Y.B., Tong, Y.Q. (2016) Development characteristics and formation mechanism of Litang luanshibao high speed and long distance landslide on the eastern edge of Qinghai Tibet Plateau, Geological Bulletin of China,35(8):1332-1345.

3. Duan, X., Tao, Y. (2007) Relationship between landslide and debris flow and precipitation under different geological and geomorphic conditions in Yunnan Province, Meteorological Monthly, 33(9): 33-39.

4. Luxmoore R.J.(1981)Microporosity, mesoporosity, and macroporosity of soil, Soil Science Society of America Journal,(03):671-672

5. Jiang, W.W., Yu, S.Q., Zhou, G.M.(2002) Study on water conservation function of different forest plants in Anji area, Acta Agriculturae Universitatis Jiangxiensis, 24(25):635-639

6. Liu, Z.T.(1981) Influence of forest on Runoff in Guancen mountain forest area of Shanxi Province, Bulletin of Soil and Water Conservation,(4):56-61

7. Liu, Y.W., Tang, C., Li,T.F.(2009) Study on the relationship between geological disasters and rainfall patterns, Journal of Engineering Geology, 17(5): 656-661

8. Cui, P., Ma, D.T., Chen, N.S.(2003) Formation, evolution and Disaster Reduction Countermeasures of ice lake outburst debris flow, Quaternary Sciences, 23(6): 621-628

9. Zhang, Y.B.(2018) Research on Risk Control and System Perfection of Emergency Command System, Journal of Catastrophology , 33(3):184-189 